\title{
TEORIAS FONOLÓGICAS E SEUS PRIMITIVOS DE ANÁLISE
}

\section{PHONOLOGICAL THEORIES AND THEIR PRIMITIVES OF ANALYSIS}

\author{
Luciane Trennephol da Costa* \\ UNICENTRO-UEPG
}

Resumo: Neste texto, discutem-se e explicitam-se os primitivos de análise no domínio sonoro ou componente fônico de três teorias marcantes na história da Linguística: a Fonologia Estruturalista (SAUSSURE, 2012) e o conceito de fonema como um som da cadeia sonora da fala que tenha a funcionalidade de uma unidade distintiva; a Fonologia Gerativa (CHOMSKY; HALLE, 1968) e o conceito de traço distintivo como propriedades mínimas de caráter acústico ou articulatório e binárias que compõem simultaneamente os sons da fala; e, por último, no escopo da Fonologia de Laboratório, a Fonologia Gestual (BROWMAN; GOLDSTEIN, 1992) e o conceito de gesto articulatório, uma unidade de análise que contempla o categórico e o variável, abordando a gradiência da fala. Após apresentar as três teorias selecionadas e seus primitivos de análise, menciona-se a abordagem possível de cada teoria na interface fonética e fonologia.

Palavras-chave: Fonologia. Estruturalismo. Gerativismo. Fonologia Gestual.

\begin{abstract}
In this text, the primitives of analysis in the sound domain or phonic component of three remarkable theories in the history of Linguistics are discussed and made explicit: the Structuralist Phonology (SAUSSURE, 2012) and the concept of phoneme as a segment of the speech sound chain that has a distinctive unit functionality; the Generative Phonology (CHOMSKY; HALLE, 1968) and the concept of distinctive features as minimal binary properties (acoustic or articulatory) that simultaneously compose speech sounds; and, finally, in the scope of Laboratory Phonology, the Gestural Phonology (BROWMAN; GOLDSTEIN, 1992) and the concept of articulatory gesture, an analysis unit that includes categorical and variable perception, addressing the speech gradience. After presenting the three selected theories and their primitives of analysis, the possible approach of each theory in the phonetic and phonology interface is then mentioned.
\end{abstract}

Keywords: Phonology. Structuralism. Gerativism. Gestural Phonology.

\footnotetext{
* Doutora em Letras pela Universidade Federal do Paraná (2011). Professora Adjunta C na Universidade Estadual do CentroOeste (UNICENTRO). Docente vinculada ao Programa de Pós-Graduação em Estudos da Linguagem da Universidade Estadual de Ponta Grossa (UEPG). Membro do Programa Permanente de Extensão Núcleo de Estudos Eslavos (NEES) e coordenadora do Laboratório de Fonética e Fonologia do NEES. ORCID: https://orcid.org/0000-0002-0223-7787. E-mail: Itcosta@unicentro.br.
} 


\section{INTRODUÇÃO}

Ao tratar do objeto da Linguística no terceiro capítulo do Cours, Saussure (2012), considerado o pai da linguística como corpo de estudo específico, nos traz esta explicação acerca do objeto científico, afirmando que ele é constituído pelo olhar do investigador: "Bem longe de dizer que o objeto precede o ponto de vista, diríamos que é o ponto de vista que cria o objeto; aliás, nada nos diz de antemão que uma dessas maneiras de considerar o fato em questão seja anterior ou superior às outras” (SAUSSURE, 2012, p. 39). Nesse sentido, a área dos estudos fônicos tem sido bem produtiva em pontos de vista e em formulações teóricas para explicitar os fenômenos sonoros encontrados nas línguas.

Assim sendo, neste texto, apresentado anteriormente no Ciclo de Palestras do Grupo de Pesquisa Laboratório de Teoria e Análise Linguística (LABTAL), da Universidade Estadual de Ponta Grossa (UEPG), em 2019, e direcionado a alunos de Graduação em Letras, selecionamos três teorias marcantes na história da Linguística e suas abordagens no componente sonoro para explicitar e problematizar seus primitivos de análise. A exposição apresentada aqui focou-se no primitivo de análise e nos postulados teóricos que o embasam e caracteriza-se como um panorama introdutório à área.

Começamos com a Fonologia Estruturalista e o conceito de fonema como um som da cadeia sonora da fala que tenha a funcionalidade de uma unidade distintiva (SAUSSURE, 2012). Em seguida, abordamos a Fonologia Gerativa (CHOMSKY; HALLE, 1968) e o conceito de traço distintivo como propriedades mínimas de caráter acústico ou articulatório e binárias que compõem simultaneamente os sons da fala. E, por último, no escopo da Fonologia de Laboratório, a Fonologia Gestual (BROWMAN; GOLDSTEIN, 1992) e o conceito de gesto articulatório, uma unidade de análise que contempla o categórico e o variável, abordando a gradiência da fala.

O critério de seleção das abordagens teóricas estruturalista e gerativista para a gramática sonora pautou-se em sua relevância na história da linguística e sua presença nos currículos de Graduação em Letras. A Fonologia Gestual é uma escolha pautada na formação acadêmica da autora deste texto e por sua proeminência atual como abordagem no que se chama Fonologia de Laboratório. Como toda seleção, ação que pressupõe escolhas, esta exclui outras abordagens teóricas também importantes e produtivas na explicitação de fenômenos sonoros como, por exemplo, a Fonologia de Uso (BYBEE, 2001) e a Teoria da Otimidade (PRINCE; SMOLENSKY, 2004).

Como primitivo de análise, entendemos aqui a unidade mínima que constitui o objeto de investigação. A depender da perspectiva com a qual observamos o nosso fenômeno linguístico, tão plural e complexo, teremos diferentes unidades mínimas para esse objeto. O primitivo variará a depender da abordagem teórica e, também, do domínio gramatical que estejamos investigando: fonético, fonológico, morfológico, sintático, discursivo. Como a citação do Saussure no nosso início nos lembra, o ponto de vista cria o objeto de investigação. No caso do campo de estudos sonoros, isso é muito marcante. Cada teoria, ao formular sua explicitação de como funciona o componente sonoro das línguas, institui o seu primitivo de análise.

Apesar de citarmos os principais teóricos de cada abordagem apresentada aqui, de maneira coerente com a natureza revisionista e didática deste texto, acreditamos que as explicações científicas são possibilitadas pelo contexto social e histórico em que viviam tais sujeitos. Nosso foco são os pressupostos teóricos de cada abordagem e suas explicitações para os fenômenos sonoros. 
Em oposição à teoria personalista da história científica, que atribui os avanços e as inovações à vontade e à força de figuras singulares, temos a teoria naturalista que inclui o sucesso dessas personalidades a um fator contextual chamado Zeitgeist (SCHULTZ; SCHULTZ, 1981, p. 27), o espírito ou clima intelectual de uma dada época. O Zeitgeist é como o padrão dominante de pensamento em dada cultura e época. Sua teoria explica por que, às vezes, grandes invenções ou teorias não são aceitas e afirmam que se tal grande cientista não tivesse formulado sua teoria, outro o teria feito. Se, por exemplo, Darwin tivesse morrido jovem, outro cientista teria formulado a teoria da evolução na metade do século XIX. Nessa abordagem, os grandes cientistas foram as personas que melhor formularam ou compilaram os novos conceitos latentes. A teoria do Zeitgeist não tira o mérito dos grandes cientistas, só os insere na sua dimensão histórica.

Este texto estrutura-se em três seções, cada uma delas dedicada a uma das abordagens teóricas selecionadas, com o intuito de explicitar seus conceitos basilares e seu primitivo de análise na gramática sonora. Para finalizar, tecemos algumas considerações acerca da abordagem possível em cada teoria para a interface entre a Fonética, tradicionalmente vista como o estudo dos aspectos físicos da fala, e a Fonologia, vista como o estudo da organização sonora das línguas.

\section{ESTRUTURALISMO E FONEMA}

Iniciamos nossa trajetória com o estruturalismo, vertente teórica produtiva nas ciências humanas do século XX e que marcou a legitimidade do nosso campo de investigação como científico. $\mathrm{O}$ estruturalismo foi considerado a primeira escola americana de pensamento no campo da psicologia (SCHULTZ; SCHULTZ, 1981, p. 105) e teve ampla repercussão também na antropologia (FIGUEIREDO, 1995). Lévi-Strauss, fundador da antropologia estrutural e que viveu no Brasil, lecionando na Universidade de São Paulo nos anos trinta do século XX, reconheceu o papel de ponta da linguística estruturalista nas ciências sociais. Segundo o autor:

No conjunto das ciências sociais, ao qual ela indiscutivelmente pertence, a linguística ocupa um lugar excepcional: não é uma ciência social como as outras mas aquela que, de longe, realizou os maiores progressos; é certamente a única que pode reivindicar o nome de ciência e que conseguiu ao mesmo tempo formular um método positivo e conhecer a natureza dos fatos que lhe cabe analisar. (LÉVISTRAUSS, 1967, p. 43).

Lévi-Strauss aplicou os conceitos e os métodos da Fonologia Estruturalista aos sistemas de parentescos nas diferentes sociedades. Vamos citá-lo mais uma vez para que nos apresente os pressupostos da linguística estrutural:

A fonologia desempenha, em relação às ciências sociais, o papel renovador que a física nuclear, por exemplo, desempenhou para o conjunto das ciências exatas. Em que consiste essa inovação, quando tentamos encará-la em suas implicações mais gerais? A resposta a essa pergunta nos é dada pelo ilustre mestre da fonologia N. Troubetzkoy. Num artigo programático (de 1933) ele resume o método fonológico a quatro procedimentos fundamentais: em primeiro lugar, a fonologia passa do estudo dos fenômenos linguísticos conscientes para o de sua infra-estrutura 
inconsciente, recusa-se a tratar os termos como entidades independentes, tomando como base de sua análise, ao contrário, as relações entre os termos; introduz a noção de sistema [...] finalmente, ela visa a descoberta de leis gerais [...]. (LÉVISTRAUSS, 1967, p. 45, grifos do autor).

Estudar a estrutura inconsciente é justamente um dos pilares da abordagem estruturalista, pois investigar a estrutura ou sistema subjacente possibilita o uso palpável e consciente das formas de tal sistema. Neste o valor das formas dá-se em relação de oposição e complementariedade, a forma só tem seu valor considerada no contexto do sistema que é regido por leis gerais. Nessa perspectiva teórica, as formas funcionais ou os primitivos de análise são os fonemas, os sons ou as unidades sonoras distintivas na língua.

Saussure foi o expoente no conjunto de grandes estruturalistas que reconheceram a função distintiva dos sons para a significação. Conforme Abaurre (1993) ${ }^{1}$ afirma:

O que essas anotações indicam é que já havia linguistas (Como Courtenay e Jespersen, para ficarmos com apenas dois nomes bastante conhecidos...), precursores de Saussure (cujo Cours de Linguistique Générale foi publicado em 1916), preocupados com a função eminentemente distintiva dos elementos fônicos que contribuem para marcar as diferenças de significação entre as palavras da língua. (ABAURRE, 1993, p. 12).

A definição de fonema do linguista polonês Jan Baduin de Courtenay é psicológica e abstrata: “Ze stanowiska psychologicznego zamiast terminu ‘dźwięk’ lub ‘głoska', oznaczającego tylko jedno ze stadjów mimolotnego, chwilowego uzewnętrzniania tego, co istnieje tylko psychicznie, wprowadzamy termin fonema” (COURTENAY, 1915, p. 163). Uma possível tradução seria: “A partir da posição psicológica, em vez do termo ‘som’ que significa apenas um dos estágios de uma externalização involuntária e temporária do que existe apenas mentalmente, introduzimos o termo phonema"2; desse modo, o fonema é uma entidade totalmente abstrata, existe apenas mentalmente. Para Courtenay (1915), os sons da linguagem existem em potência na mente do falante e se concretizam a partir das possibilidades de produção do aparelho vocal humano: “Dźwięki języka są tylko możliwe ,są tylko in potentia, ale nie istnieją. Jednakże możliwość wymawiania istnieje ciągle, a tem status in potentia staje się w razie potrzeby status in actu" (COURTENAY, 1915, p. 163). Uma possível tradução seria: "Sons de linguagem são somente possíveis, são apenas in potentia, mas eles não existem. No entanto, a capacidade de pronunciar sempre está lá, sempre existe, e esse status in potentia, se necessário, torna-se status in actu”.

O fonema é então uma entidade abstrata, que existe como tal apenas na mente do falante; e a unidade sonora distintiva, no sistema linguístico. Nem toda emissão fônica tem valor distintivo no sistema. Por meio da metodologia de pares mínimos, sequência sonora com sentido diferente e que contrasta em apenas um som, o pesquisador chegará aos sons de uma língua. Por exemplo, em uma das línguas faladas no Paraná, a língua polonesa, o conjunto kot [kot] (gato) e koń [kэn] (cavalo), sequências nas quais diferem apenas os sons [t] e [n], comprova que esses sons são fonemas no polonês, a oclusiva /t/ e a nasal /n/. A notação [t] é usada para

\footnotetext{
${ }^{1} \mathrm{O}$ texto de Abaurre traz um panorama histórico e explicativo detalhado acerca do estruturalismo e do gerativismo nos estudos fônicos. ${ }^{2}$ Agradeço à professora Izabela Stąpor da Universidade de Varsóvia pelo auxílio nas traduções. Eventuais erros são de minha responsabilidade.
} 
transcrição fonética e a notação /t/ para transcrição fonológica. Se a mudança de um som não altera o significado da palavra, esse som não é um fonema na língua em questão. Por exemplo, na língua portuguesa, temos o clássico exemplo da oclusiva alveolar e seu alofone, variação de um fonema, a africada [ $\mathrm{t}$ ] . O conjunto tia [tia] e [tia] com o mesmo significado, irmã do pai ou da mãe, comprova que o som [ $\mathrm{t}$ ] não é um fonema na nossa língua, mas um alofone da oclusiva alveolar [t] no contexto de suceder uma vogal alta anterior [i]. Apenas é fonema o som que tem valor distintivo em dada língua. O fonema é a forma e suas possíveis variações que funcionam como uma unidade valorativa no sistema abstrato da língua em questão. No caso do exemplo anterior do e no português, [t] e [t'] têm o mesmo valor no sistema, embora possam ser articulatória e acusticamente diferentes. Veja-se que o conceito de fonema encaixa-se perfeitamente na dicotomia saussureana langue e parole. $\mathrm{O}$ fonema, forma distintiva funcional, está na língua, no sistema abstrato e é uma representação mental; e a forma pronunciada, que pode variar sua produção, está na fala. A língua é o sistema subjacente que permite a realização concreta e palpável ou observável, a fala. Perfeitamente estrutural.

No entanto, o que permite a variação da forma distintiva? Alguma característica fonética em dado contexto. No caso da oclusiva alveolar no português, o contexto adjacente da vogal alta anterior como vimos no parágrafo anterior. Saussure (2012, p. 77) já define o fonema como a soma das impressões acústicas e dos movimentos articulatórios. Esse conceito do fonema como traços que ocorrem em conjunto ou feixe vai ser desenvolvido após Saussure pelo chamado Círculo Linguístico de Praga, que unia Trubetzkoy, Jakobson e Karcevsky e marcou a fundação da Fonologia, em 1928, no $1^{\circ}$ Congresso Internacional de Linguística, realizado em Haia. O primeiro conjunto de traços de base articulatória foi proposto por Jakobson, Fant e Halle em Preliminaries to Speech Analysis, o PSA (1976). É como se eles observassem o fonema em um microscópio: "The distinctives features are the ultimate distinctive entities of language since no one of them can be broken down into smaller linguistic units" (JAKOBSON; FANT; HALLE, 1976, p. 3) $)^{3}$. Rumava-se para o primitivo da fonologia gerativa do qual trataremos na próxima seção.

\section{GERATIVISMO E TRAÇO DISTINTIVO}

A abordagem gerativa para o componente sonoro foi explicitada em The Sound Pattern of English, de Chomsky e Halle (1968), o chamado SPE. A teoria gerativa foi mudando com o transcorrer do tempo e passou por vários modelos, aqui nos ateremos à teoria gerativa clássica. Nela a capacidade linguística humana justifica-se biologicamente. A espécie humana é dotada com a GU, a Gramática Universal, que contém todas as possibilidades linguísticas. É um postulado forte da teoria, a característica genética para a linguagem e a base comum para todas as línguas. A aquisição linguística marca e define as especificidades da língua materna, ou línguas, pela ação desencadeante do estímulo a que a criança é exposta. O componente gramatical divide-se em competência, o conhecimento inconsciente do falante, e desempenho, o uso efetivo em situações concretas. A competência explica porque um falante nativo de português ao confrontar-se com a frase "Pedro potechou calamente o motole" provavelmente

\footnotetext{
3 “Os traços distintivos são as últimas entidades da língua já que nenhum deles pode ser dividido em unidades menores” (JAKOBSON; FANT; HALLE, 1976, p. 3, tradução nossa).
} 
reconhecerá que a segunda palavra e a terceira poderiam pertencer à língua portuguesa. Não existem na língua, mas suas estruturas são de verbo e de advérbio. ${ }^{4} \mathrm{O}$ falante nativo, não especialista em linguagem como nós, linguistas, pode não saber definir o que é um verbo ou um advérbio, mas reconhecerá essas palavras como possíveis na língua. As palavras estão nas regras da língua portuguesa, apesar de não existirem no seu léxico. Também esse componente gramatical é dividido em módulos sucessivos (semântico $>$ sintático $>$ fonológico $>$ fonético) entre os quais operam as regras gramaticais da língua em questão. A gramática gerativa pretende explicitar, além de descrever, como são geradas as formas linguísticas. Regras aplicadas na forma fonológica subjacente geram a forma fonética superficial: “O componente fonológico é, então, definido como a parte da gramática que atribui uma interpretação fonética à descrição sintática” (HERNANDORENA, 2001, p. 15).

Se a representação dos itens lexicais especifica traços semânticos, como [animado ou inanimado, humano ou não-humano], a representação fonológica de cada segmento fônico agrupa especificações de traços fonéticos. Eles são então as unidades mínimas presentes na representação fonológica, os seus primitivos de análise. O conjunto de traços fonéticos relaciona-se às capacidades humanas de articulação e, coerentemente com a teoria, seria universal: "The total set of features is identical with the set of phonetic properties that can in principle be controlled in speech; they represent the phonetic capabilities of man and, we would assume, are therefore the same for all languages"5 (CHOMSKY; HALLE, 1968, p. 295).

Os traços podem ser definidos então como “[...] propriedades mínimas, de caráter acústico ou articulatório, como 'nasalidade', 'sonoridade', 'labialidade', 'coronalidade', que, de forma coocorrente, constituem os sons da língua” (HERNANDORENA, 2001, p. 17). Na representação fonológica subjacente, eles são marcadores binários, positivo ou presença e negativo ou ausência. Não vamos definir aqui todo o conjunto de traços do SPE, mas apenas aqueles que especificariam as classes principais de segmentos. Eles são três: sonorante ou não sonorante (obstruinte), vocálico ou não vocálico e consonantal ou não consonantal. Sonorantes são sons produzidos com uma configuração do trato vocal no qual o vozeamento espontâneo é possível, obstruintes são produzidas com uma configuração que torna o vozeamento espontâneo impossível. Vocálicos são sons produzidos sem uma constrição radical no trato oral, essa constrição não excede aquela feita para produzir as vogais altas [i] e [u], e as cordas vocais estão posicionadas de modo a permitir o vozeamento espontâneo. Já Consonantais são sons produzidos com uma constrição radical no trato oral.

Posteriormente, no próprio SPE, o traço Vocálico é substituído pelo traço Silábico, definido como um traço presente em segmentos que podem constituir pico ou núcleo de sílaba (HERNANDORENA, 2001). Este é um procedimento da teoria gerativa, a partir da observação dos fenômenos linguísticos: modificam-se os postulados. A troca do traço vocálico por silábico deu-se a partir da constatação de que, às vezes, segmentos não vocálicos podem ser núcleo de sílaba em algumas línguas. Assim a presença ou ausência desses três traços de classes principais formaria as classes naturais de sons. Por exemplo, uma vogal seria especificada como

\footnotetext{
${ }^{4} \mathrm{O}$ exemplo dado em Chomsky e Halle para a língua inglesa: "Pirots karullized elatically”.

5 “ "O conjunto total de traços é idêntico ao conjunto das propriedades fonéticas que podem ser controladas na fala, os traços representam as capacidades fonéticas dos homens e, poderíamos supor, são, portanto, os mesmos para todas as línguas.”(CHOMSKY; HALLE, 1968, p. 295, tradução nossa).
} 
[+ sonorante, - consonantal, + silábica], já uma consoante como [-sonorante, + consonantal, - silábica]. Cada segmento tem uma especificação própria de traços fonéticos que ocorrem simultaneamente e a diferença de um traço ou mais é que diferencia os sons da fala. Essas especificações são agrupadas em matrizes, como podemos visualizar na Figura 1:

Figura 1: Representação de matrizes de traços para os segmentos /t/ e /d/

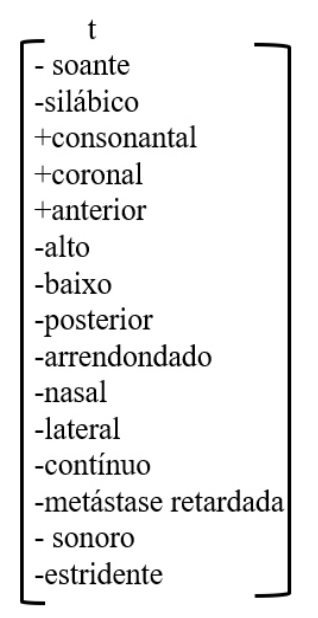

$$
\left[\begin{array}{l}
\quad \mathrm{d} \\
\text { - soante } \\
\text { - silábico } \\
\text { + consonantal } \\
+ \text { coronal } \\
+ \text { anterior } \\
\text {-alto } \\
\text {-baixo } \\
\text {-posterior } \\
\text {-arrendodado } \\
\text {-nasal } \\
\text {-lateral } \\
\text {-contínuo } \\
\text {-metástase retardada } \\
\text { +sonoro } \\
\text {-estridente }
\end{array}\right]
$$

Fonte: Adaptada de Hernandorena (2001, p. 25).

Nessa representação de matrizes para os segmentos /t/ e/d/ apenas um traço os diferencia: o sonoro. Nesse modelo de matrizes de traços, chamado Modelo Linear, a ordem dos segmentos era aleatória, mas com a observação dos fenômenos, a teoria evoluiu para modelos não-lineares que consideram a existência de uma estrutura hierárquica para o conjunto de traços dos segmentos. A ordem não é mais aleatória, mas, sim, justificada pela capacidade de assimilação ou deleção de traços, por exemplo. Vamos ilustrar aqui com uma proposta de representação dos róticos, sons de r, para a língua Igbo presente em Dickey (1997):

Figura 2: Representação para os róticos do Igbo
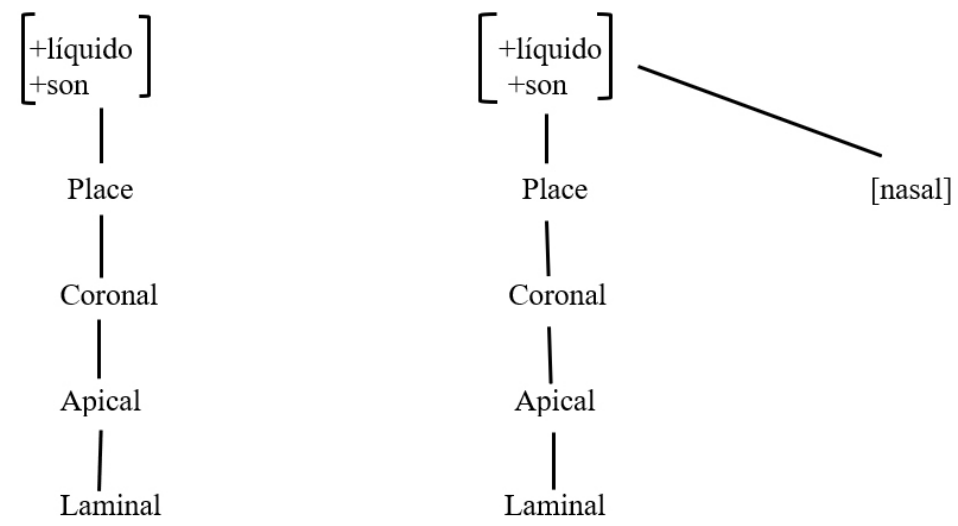

Fonte: Dickey (1997, p. 151). 
O leitor perceberá que, nessa representação, temos a postulação da existência do traço [líquido] nos traços principais, hipótese defendida por Dickey (1997) para dar conta da representação dos sons líquidos, classe que agrupa os sons laterais e róticos, a partir da observação de fenômenos em variadas línguas. A representação à direita da figura mostra a presença da nasalização do rótico com a adição do traço [nasal]. Esses modelos chamados de Geometria de Traços ilustram a possibilidade de um traço ser deletado ou espraiado com a aplicação das regras fonológicas da língua em questão. Assim, o traço nasal na representação anterior liga-se diretamente aos traços de raiz para justificar a nasalização dos róticos no Igbo. A sua ausência ou corte não muda radicalmente a estrutura do segmento, ele continua a ser um rótico sem a nasalização. Esses traços, envolvidos em processos de assimilação e outros processos entre segmentos, estariam representados de forma a serem deletados sem alterar a essência do segmento.

As postulações de traços distintivos para os segmentos faziam-se então baseadas nas observações dos fenômenos, e o poder formalista e abstrato da teoria foi grande, pois as explicações para os fenômenos sonoros geravam as representações mentais. Com o desenvolvimento e a socialização crescente da tecnologia no século XX, a possibilidade de observações instrumentais realizadas em laboratórios de fonética acústica e aparelhos ultrassonográficos que permitem a observação articulatória, despontam outros tipos de abordagens teóricas para a Fonologia que consideram a observação da produção ou realização sonora, como é o caso da terceira abordagem que apresentamos a seguir.

\section{FONOLOGIA GESTUAL E O GESTO ARTICULATÓRIO}

No escopo da Fonologia de Laboratório, denominação que agrega abordagens teóricas desenvolvidas com base em técnicas de laboratório, principalmente análise fonética acústica, a Fonologia Gestual ou Articulatory Phonology (BROWMAN; GOLDSTEIN, 1992) vai definir como seu primitivo de análise o gesto articulatório: "In articulatory phonology, the basic units of phonological contrast are gestures, which are also abstract characterizations of articulatory events, each with an intrinsic time or duration"6 (BROWMAN; GOLDSTEIN, 1992, p. 155). O gesto articulatório não deve ser confundido com os gestos feitos nas manobras articulatórias para a produção sonora, eles são caracterizações abstratas dotadas de especificação temporal.

O termo Fonologia Gestual evita uma ligação mnemônica com a Fonética Articulatória e marca a especificidade teórica dessa abordagem, pois o gesto é uma oscilação abstrata em termos de uma dinâmica de tarefa que envolve os articuladores e não apenas o movimento dos articuladores implicados na atividade de fala (COSTA, 2012). Uma dinâmica de tarefa engloba ações coordenadas de vários articuladores (SALTZMAN; KELSO, 1987) e seus parâmetros podem exibir flutuações devido às perturbações normais do sistema com a relação entre os articuladores. Na fala temos então a ação coordenada de vários articuladores cujos movimentos se influenciam mutuamente. Podemos fazer uma metáfora com a ação de caminhar, ação na qual também temos vários articuladores agindo em conjunto para o movimento. Um sistema dinâmico pode ser definido como um conjunto de variáveis quantitativas como, por exemplo,

\footnotetext{
6 “Na fonologia articulatória, as unidades básicas de contraste fonológico são os gestos, que também são caracterizações abstratas de eventos articulatórios, cada um com um tempo ou duração intrínseca.” (BROWMAN; GOLDSTEIN, 1992, p. 155, tradução nossa).
} 
distância, ativações de articuladores, velocidade de mudança que mudam simultaneamente no transcorrer do tempo devido a influências de uma variável sobre outra (PORT, 2002).

Os gestos são definidos em termos de dinâmica de tarefa porque envolvem a formação e soltura de constrições no trato vocal com tempo intrínseco. O que é caracterizado dinamicamente não é o movimento isolado dos articuladores, mas, sim, o movimento de variáveis do trato. Na Fonologia Gestual, temos cinco variáveis do trato e cada uma delas caracteriza a dimensão da constrição em local e grau e os articuladores envolvidos. No Quadro 1, temos as cinco variáveis do trato. As ações conjuntas dos articuladores constituem as variáveis do trato que relacionadas implementam os gestos articulatórios; como o local e o grau são dimensões de uma mesma constrição, eles estão alocados na mesma linha.

Quadro 1: Variáveis do trato na Fonologia Gestual

\begin{tabular}{|l|l|}
\hline \multicolumn{1}{|c|}{ Variáveis do trato } & \multicolumn{1}{c|}{ Articuladores envolvidos } \\
\hline $\begin{array}{l}\text { LP protusão labial } \\
\text { LA abertura labial }\end{array}$ & Lábios inferior e superior, mandíbula \\
\hline $\begin{array}{l}\text { TTCL local de constrição da ponta de língua } \\
\text { TTCD grau de constrição da ponta de língua }\end{array}$ & Ponta e corpo de língua, mandíbula \\
\hline $\begin{array}{l}\text { TBCL local de constrição do corpo de língua } \\
\text { TBCD grau de constrição do corpo de língua }\end{array}$ & Corpo de língua, mandíbula \\
\hline VEL abertura vélica & Véu palatino \\
\hline GLO abertura glotal & Glote \\
\hline
\end{tabular}

Fonte: Adaptado de Browman e Goldstein (1992, p. 157).

No Quadro 1, mantivemos as maiúsculas iniciais das variáveis como na fonte original, elas são as iniciais da variável do trato em inglês, por exemplo, TTCL são as letras iniciais para tongue tip constrict location e TTCD são as letras iniciais para tongue tip constrict degree. O gesto de protusão labial envolve assim a ação coordenada de três articuladores: lábios inferior e superior e a mandíbula. Já um gesto de corpo de língua, envolvido na produção dos sons vocálicos, envolve a ação coordenada do corpo de língua e da mandíbula. Os gestos são as unidades básicas, ou primitivos, de contraste fonológico; assim, dois itens lexicais diferem se tiverem composição gestual diferente. Essa diferença pode concretizar-se pela presença ou ausência de determinado gesto, por diferenças nos parâmetros dos gestos e por diferenças de organização dos gestos.

O modo como os gestos são organizados para formar os sons da fala chama-se faseamento e é representado na teoria com a pauta gestual. Na Figura 3, apresentamos uma pauta gestual para a palavra pata. Os gestos são eventos físicos que ocorrem no tempo e no espaço e possuem duração, podendo sobrepor-se a outros gestos. Na pauta, o eixo horizontal ilustra o intervalo de ativação temporal do gesto e o eixo vertical ilustra a sua magnitude. A pauta ilustra também a sobreposição dos gestos. No caso da palavra pata, podemos ter a sobreposição do gesto de abertura labial para a consoante inicial com o gesto de corpo de língua para produção do som vocálico. 
Figura 4: Pauta Gestual para a palavra pata

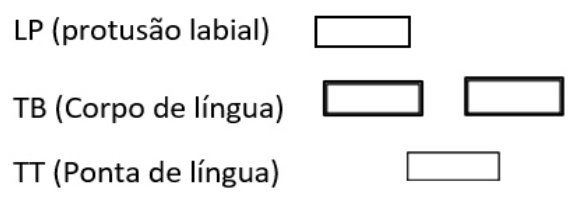

Fonte: A autora.

A sobreposição dos gestos pode ser mínima, parcial e completa. Dessa forma, a diferente organização e a sobreposição dos gestos cria os contrastes lexicais na língua. Já a maleabilidade dos gestos, consequência de sua natureza como um sistema dinâmico, gera o contínuo gradiente observado na fala e que pode manifestar-se como variação. A mesma estrutura gestual caracteriza simultaneamente as propriedades fonológicas e as físicas. Como um sistema dinâmico, o gesto consegue representar o contínuo gradiente da fala observado por meio de análises fonéticas acústicas. Podemos citar, por exemplo, o caso da sonoridade dos sons: na observação acústica, podemos constatar a natureza não categórica dessa propriedade, determinado som pode ser surdo (sem vibração das pregas vocais) ou sonoro (com vibração das pregas vocais), mas essa propriedade é escalar, apresenta níveis de sonoridade, e não apenas dicotômica, presença versus ausência. A Fonologia Gestual incorpora então a natureza gradiente dos sons e, também, modela a variação como uma cristalização de mudanças na organização e na sobreposição de gestos.

Importante destacar que, como toda abordagem teórica, inclusive as duas que já revisitamos neste texto, a Fonologia Gestual foi modificando-se e apresentando novos conceitos e postulados. No Brasil, uma abordagem chamada Fonologia Acústica - Articulatória é proposta por Albano (2001) cuja principal proposta é a existência de regiões acústico-articulatórias no trato que substituem os articuladores na função de agrupar os comandos para a execução de um gesto.

\section{CONSIDERAÇÕES FINAIS}

Nosso objetivo neste texto foi apresentar, para iniciantes na área, o primitivo de análise de três abordagens teóricas bastante produtivas e relevantes nos estudos fônicos. Nessa apresentação, abordamos brevemente os postulados teóricos implicados no conceito desses primitivos, de forma superficial, sem maiores aprofundamentos, da maneira possível no espaço de um artigo. Para finalizar, vamos agora mencionar a abordagem possível em cada teoria para a interface entre a Fonética e a Fonologia.

Vimos que o fonema, primitivo de análise do Estruturalismo, é uma entidade abstrata presente na língua, o sistema subjacente, e que, na fala, estão presentes suas variações fonéticas ou alofones. O conceito de fonema então coaduna-se com a dicotomia saussureana langue/parole ou língua/fala. Essa dicotomia é o fosso fundador da Linguística enquanto ciência independente e autônoma e foi muito eficiente nesse papel, como vimos na citação de Levi-Strauss (1967). O fosso fundador que separou língua e fala separou também radicalmente a Fonética e a Fonologia.

No Gerativismo, vimos que o primitivo era o traço fonético especificado no componente gramatical fonológico e que, com a aplicação das regras gramaticais próprias de cada língua, 
eram geradas as representações fonéticas ou superficiais. Temos dois módulos específicos: o módulo fonológico e o módulo fonético. Na representação fonológica, os traços são marcadores abstratos de presença ou ausência de tal propriedade fonética. Com a aplicação de regras, chega-se às efetivas realizações. A implementação de regras aplicadas entre um módulo gramatical fonológico e outro fonético fazem a ponte entre a fonética e a fonologia.

Na Fonologia Gestual, o primitivo de análise, o gesto, incorpora a invariância fonológica para criar o contraste lexical e a gradiência física dos sons existentes na fala. É um primitivo que permite a comensurabilidade entre a fonética e a fonologia por ser caracterizado em termos de um sistema dinâmico. A partir do desenvolvimento tecnológico que permitiu a inspeção do sinal acústico, o detalhe fonético pode ser investigado e incorporado à representação gramatical dos fenômenos. Como argumenta Silva (2010), a análise acústica deve embasar uma representação gramatical e ter precedência sobre a análise impressionística de oitiva, aquela que conta com a percepção do próprio pesquisador. Os desdobramentos teóricos da Fonologia Gestual tentam dar conta do desafio da especificação dos limites ou bordas dos gestos, em outras palavras, como seria especificado na mente do falante os limites possíveis para a realização de determinado gesto.

Contribuímos, neste texto, com um quadro panorâmico introdutório da área de estudos fônicos na Linguística, ao tratar do primitivo de análise em cada uma das três teorias selecionadas. Esperamos ter despertado o interesse nessa área tão produtiva e envolvida diretamente, por exemplo, na descrição linguística, no tratamento de fenômenos variáveis, no bilinguismo e na aprendizagem linguística.

\section{REFERÊNCIAS}

ABAURRE, M. B. M. Fonologia: a gramática dos sons. Revista Letras, Santa Maria, n. 5, 9-24, jan./jun. 1993. DOI: https://doi.org/10.5902/2176148511445

ALBANO, E. C. O gesto e suas bordas: esboço de Fonologia acústico-articulatória do português brasileiro. Campinas: Mercado das Letras, 2001.

BROWMAN, C.; GOLDSTEIN, L. Articulatory Phonology: an overview. Phonetica, [s. l.], v. 49, n. 3-4, p. 155-180, 1992. DOI: https://doi.org/10.1159/000261913

BYBEE, J. Phonology and Language Use. [S. l.]: Cambridge University Press, 2001. (Cambridge Studies in Linguistics Book 94).

CHOMSKY, N.; HALLE, M. The Sound Pattern of English. New York: Harper e Row, 1968. COSTA, L. T. Modelamento teórico de processos variáveis em modelos dinâmicos de fala: possibilidades de representação do rotacismo o âmbito da Fonologia Gestual. Letras \& Letras: Estudos em Fonologia, [s. l.], v. 28, n. 1, p. 387-404, jan./jun. 2012.

COURTENAY, J. B. Charakterystyka psychologiczna języka polskiego.In: ŁOŚ, J. et al. (org.). Język polski i jego historya $z$ uwzolędnieniem innych języków na ziemiach polskich. Kraków: Akademii Umiejętności, 1915. p. 154-170.

DICKEY, L. W. The Phonology of Liquids. 1997. Tese (Doutorado em Linguistics) University of Massachusetts Amherst, 1997. 
FIGUEIREDO, L. C. M. Matrizes do pensamento psicológico. Petrópolis: Vozes, 1995.

HERNANDORENA, C. L. Introdução à Teoria Fonológica. In: BISOL, L. (org.). Introdução a estudos de fonologia do português brasileiro. Porto Alegre: EDIPUCRS, 2001. p. 11-89.

JAKOBSON, R.; FANT, G.; HALLE, M. Preliminaries to speech analysis: the distintictive features and their correlates. Cambridge: Massachusetts Institute of Technology, 1976.

LÉVI-STRAUSS, C. Antropologia Estrutural. Rio de Janeiro: Tempo Brasileiro, 1967.

PORT, R. The dynamical systems hypothesis in Cognitive Science. In: NADEL, L. (ed.). Encyclopedia of Cognitive Science. London: Nature Publishing Group, Macmillan Company, 2002. v. 1. p. 1027-1032.

PRINCE, A.; SMOLENSKY, P. Optimality Theory: constraint interaction in Generative Grammar. In: MCCARTHY, J. J. (ed.). Optimality Theory in Phonology: a reader. [S. l.]: Blackwell Publishing Ltda., 2004. p. 3-71.

SALTZMAN, E.; KELSO, J. A. S. Skilled actions: A task-dynamic approach. Psychological Review, [s. l.], v. 94, n. 1, p. 84-106, 1987. DOI: http://dx.doi.org/10.1037/0033-295X.94.1.84

SAUSSURE, F. Curso de Linguística Geral. Tradução Antônio Chelini, José Paulo Paes, Izidoro Blikstein. 34. ed. São Paulo: Cultrix, 2012.

SCHULTZ, D.; SCHULTZ, S. História da Psicologia Moderna. São Paulo: Cultrix, 1981.

SILVA, A. H. P. O estatuto da análise acústica nos estudos fônicos. Cadernos de Letras da UFF- Dossiê: Letras e cognição, Niterói, n. 41, p. 213-229, 2010.

Recebido em: jul. 2020.

Aceito em: ago. 2020. 